\title{
Analisis Perbandingan Performa Traffic Engineering Dengan Resource Reservation Protocol (RSVP) dan Segment Routing
}

\author{
Dwi Ariyanti \\ Program Studi D4 Teknologi Rekayasa Internet \\ Universitas Gadjah Mada \\ dwiariyanti@mail.ugm.ac.id
}

\author{
Unan Yusmaniar Oktiawati \\ Program Studi D4 Teknologi Rekayasa Internet \\ Universitas Gadjah Mada \\ unan yusmaniar@ugm.ac.id
}

\begin{abstract}
Abstrak - Kualitas koneksi khususnya pada backbone menjadi tantangan Internet Service Provider (ISP). MPLS berkerja di layer 2,5 OSI yang mampu mempercepat pengiriman paket pada jaringan backbone. MPLS melekatkan label pada paket yang dikirimkan. Salah satu layanan dari MPLS adalah traffic engineering yang dibuat dengan protokol RSVP. Terdapat protokol baru untuk memberi label pada paket dan mendukung traffic engineering, yaitu Segment Routing. Penelitian ini menganalisis perbandingan performa traffic engineering dengan RSVP dan Segment Routing. Baik pada penerapan RSVP maupun Segment Routing dibuat tunnel untuk jalur utama dan reroute menuju jalur cadangan. Penelitian dilakukan pada emulator EVE-NG dengan mengambil studi kasus topologi backbone di PT ICON+.

Hasil penelitian adalah Segment Routing di MPLS menyederhanakan kinerja dari router dalam hal pelabelan dan dalam memelihara Label Switch Path (LSP), tidak membutuhkan protokol signaling. Hasil pengujian latency pada jalur utama, dengan Segment Routing maupun dengan RSVP mempunyai nilai sama. Sedangkan pada jalur cadangan, nilai latency dari Segment Routing lebih kecil, sehingga Segment Routing dapat mengirim data dengan lebih cepat daripada dengan RSVP. Hasil pengujian packet delivery ratio dan packet loss ratio dengan Segment Routing dan dengan RSVP baik di jalur utama maupun jalur cadangan bernilai sama, yaitu $100 \%$ dan $0 \%$. Baik pada jalur utama maupun jalur cadangan, penerapan Segment Routing mempunyai nilai throughput yang lebih besar daripada penerapan RSVP, sehingga Segment Routing dapat mengirim data dengan lebih cepat daripada RSVP. Pada kondisi link mengalami kegagalan saat pengujian, keduanya memiliki $1 \%$ packet loss, namun perpindahan jalur dilakukan dengan lebih cepat pada Segment Routing.

Kata Kunci: MPLS, QoS, Reroute, RSVP, Segment Routing, Traffic Engineering.
\end{abstract}

\section{PENDAHULUAN}

Di era digital ini, internet menjadi suatu kebutuhan. Hal itu dapat dilihat dari peningkatan jumlah penggunaan internet yang kian hari semakin bertambah. Berdasarkan data dari APJII, pengguna internet di Indonesia pada tahun 2017 sebanyak 143,26 juta pengguna [1]. Jumlah itu diprediksi akan semakin bertambah di tahun-tahun selanjutnya didukung oleh realisasi proyek pemerintah Palapa Ring pada tahun 2018/2019. Peningkatan pengguna internet oleh berbagai pihak mendorong ISP untuk meningkatkan kualitas layanan mereka.

Masalah yang sering dialami oleh ISP yaitu terganggunya jalur komunikasi yang disebabkan oleh putus kabel. Jalur yang terputus tentu menyebabkan layanan bagi pelanggan terganggu. Membiarkan banyak pelanggan terlalu lama menunggu perbaikan jalur di lapangan tentu bukanlah hal yang tepat. Oleh karena itu, kualitas koneksi khususnya pada backbone menjadi tantangan Internet Service Provider (ISP).

Multiprotocol Label Switching (MPLS) adalah mekanisme switching yang sering dipakai di lingkungan ISP. MPLS memanfaatkan perutean IP tradisional dan mendukung beberapa layanan yang diperlukan dalam jaringan IP generasi berikutnya, seperti traffic engineering, garansi QoS, dan VPN [2]. PT ICON+ adalah ISP yang menggunakan standar backbone jaringan MPLS untuk layanan berbasis IP. PT ICON + juga telah menerapkan metode Traffic Engineering dengan protokol RSVP.

Belum lama ini muncul paradigma baru dalam source routing yang disebut Segment Routing (SR). Segment Routing adalah teknologi penerusan paket dengan jalur yang ditentukan oleh source node, kemudian paket dikirim melalui node tertentu dan jalur penerusan yang disebut Segment. IETF mengatakan bahwa Segment Routing dapat langsung diterapkan ke arsitektur MPLS tanpa perubahan pada forwarding plane [3]. Segment Routing dapat diterapkan pada jaringan MPLS sebagai pengganti LDP dalam hal pertukaran label dan RSVP dalam hal traffic engineering.

Penelitian ini akan membandingkan performa traffic engineering dengan RSVP dan Segment Routing pada MPLS. Penelitian menerapkan mekanisme reroute untuk mengalihkan jalur utama ke jalur cadangan ketika jalur utama putus. Penelitian dilakukan secara simulasi di emulator EVENG karena keterbatasan akses peneliti ke jaringan backbone dan menghindari terganggunya proses bisnis perusahaan jika langsung diimplementasikan pada jaringan yang sudah ada. 
Penelitian tentang reroute pada MPLS TE sebelumnya sudah pernah dilakukan. Penelitian berjudul "Implementation of Fast Reroute Configuration with Link and Node Protection in MPLS" menjelaskan konfigurasi dan cara kerja dari link protection, node protection, hingga RSVP fast reroute. Tujuan akhir dari fitur-fitur tersebut adalah untuk membuat secondary path pada jaringan MPLS Traffic Engineering. Secondary path yaitu jalur cadangan yang digunakan ketika jalur utama mengalami kegagalan [4].

Penelitian lain berjudul "Analisis Jaringan MPLS-TE Fast Reroute Menggunakan Metode QoS Diffserv Berbasis Server OpenIMSCore" menerangkan bahwa Fast Reroute pada MPLS TE dapat digunakan sebagai backup link ketika terjadi failed link [5]. Penelitian dilakukan secara simulasi pada GNS3. Pengujian dilakukan dengan melewatkan paket VoIP dan Video. Skenario yang digunakan yaitu pengujian pada link normal dan pengujian pada saat terjadi pemutusan link. Hasil pengujian menunjukkan bahwa delay ketika terjadi pemutusan link lebih besar daripada delay pada link normal. Nilai delay mempengaruhi jitter dan throughput. Pada penelitian ini ketika terjadi pemutusan link, nilai jitter dan throughput menjadi lebih kecil daripada ketika link normal.

Backup link memiliki peranan penting dalam menjaga ketersediaan jaringan. Pada MPLS dengan RSVP terdapat mekanisme Fast Reroute, di Segment Routing juga terdapat mekanisme untuk membuat backup link. Mekanisme tersebut adalah Topology Independent-Loop Free Alternate (TI-LFA). Peter Prjevara \& Fouad Makioui melakukan penelitian tentang jalur cadangan TI-LFA melalui proyek SURFnet [6]. Penelitian menggunakan 8 router Juniper yang disusun membentuk topologi SURFnet. TI-LFA dikonfigurasi di source router dan kinerjanya diuji ketika terjadi kegagalan link. Adapun kegagalan link disimulasikan dengan melepas kabel dari interface. Sebelum diterapkan TI-LFA, rata-rata pemulihan sebesar $304 \mathrm{~ms}$, setelah diterapkan TI-LFA menjadi $26 \mathrm{~ms}$. Peneliti membuktikan bahwa TI-LFA adalah cara yang efisien untuk kalkulasi jalur cadangan.

\section{METODOLOGI PENELITIAN}

\section{A. Multiprotocol Label Switching (MPLS)}

Multiprotocol Label Switching (MPLS) merupakan pemodelan jaringan yang bekerja pada layer 2,5 OSI dengan cara melekatkan label pada paket [7]. MPLS memungkinkan router untuk meneruskan paket dengan hanya melihat label dari paket itu, tidak perlu melihat IP alamat tujuannya. Tujuan dari MPLS berkaitan dengan label swapping [8]. Label swapping berguna untuk memisahkan masalah routing dan forwarding.

\section{B. MPLS RSVP-TE}

Koneksi WAN pada ISP membutuhkan biaya yang mahal. Mengurangi biaya adalah salah satu tujuan dari diterapkannya traffic engineering pada jaringan. Penghematan biaya yang berasal dari penggunaan resource yang lebih efisien akan membantu mengurangi total biaya operasional. Seperti pada penerapannya, traffic engineering dapat digunakan untuk mengontrol traffic flow. Selain itu, juga dapat digunakan untuk memberikan perlindungan terharap kegagalan link atau node dengan menyediakan backup tunnel [2].

Informasi traffic engineering pada MPLS dibawa oleh protokol RSVP. RSVP digunakan pada MPLS Traffic Engineering untuk memberi sinyal LSP pada suatu tunnel TE baik yang dibangun secara dinamis (dynamic path) maupun yang didefinisikan secara eksplisit (explicit path) [9]. Traffic engineering dapat digunakan untuk mengubah LSP yang secara default dipilih oleh IGP melalui jalur terpendek.

\section{Segment Routing}

Menurut IETF, Segment Routing (SR) memanfaatkan paradigma perutean sumber (source-based routing). Node mengarahkan paket melalui daftar instruksi yang diurutkan, yang disebut segment. Sebuah segment dapat mewakili instruksi, topologi atau layanan apapun. SR menyediakan mekanisme yang memungkinkan aliran dibatasi ke jalur topologi tertentu, sambil mengelola state hanya di simpul masuk ke domain Segment Routing [3]. Segment Routing dapat langsung diterapkan ke arsitektur MPLS tanpa perubahan pada forwarding plane. Segment dikodekan sebagai label MPLS.

Segment Routing menggunakan segment dan segment identifier (SID) dalam meneruskan paket. Segment adalah unit dasar dari Segment Routing. Pada Segment Routing, dikenal istilah IGP segment. IGP segment berfungsi untuk mendistribusikan 2 tipe segment, yaitu Prefix segment dan Adjacency segment [10]. Setiap node (router) dan setiap link (adjacency) mempunyai segment identifier (SID). Prefix-SID dikonfigurasi secara manual melalui Segment Routing Global Block (SRGB) dan didistribusikan oleh protokol link-state, ISIS atau OSPF. Prefix segment mengarahkan traffic menuju tujuan melalui jalur terpendek. Prefix segment dikonfigurasikan di interface loopback dari router. Adjacency segment bersifat lokal, router yang satu dapat mempunyai label yang sama dengan router lain. Adjacency segment juga didistribusikan oleh protokol link-state, berfungsi untuk mengarahkan traffic ke adjacency tertentu, seperti egress interface ke router tetangga.

\section{Segment Routing Traffic Engineering}

SRTE mendukung explicit routing dan contraints-based routing seperti RSVP-TE. Namun tidak seperti RSVP, SRTE tidak membutuhkan state sehingga memberikan kesederhanaan dan skalabilitas. SRTE mendukung reroute dengan Topology Independent-Loop Free Alternate (TI-LFA) yang digunakan dalam perlindungan kegagalan link atau node pada jaringan.

\section{E. Emulated Virtual Environment-Next Generation (EVE- NG)}

EVE-NG adalah tool yang digunakan untuk membuat simulasi jaringan, menghubungkan perangkat virtual dengan perangkat virtual lain dan perangkat virtual dengan komputer sungguhan [11]. Server EVE-NG berupa sistem operasi Linux berbasis Ubuntu yang dapat di-install secara langsung di 
komputer. Selain itu, EVE-NG juga dapat di-install di mesin virtual seperti VMWare.

Antarmuka EVE-NG diakses melalui web browser dengan menggunakan alamat IP dari server EVE-NG. Oleh karena itu, EVE-NG dapat diakses dimanapun pengguna berada tanpa harus membawa komputer yang ter-install server. Selain itu, EVE-NG dapat digunakan secara multiuser, sehingga beberapa orang dapat mengerjakan lab dalam waktu yang bersamaan dalam satu server.

\section{HASIL DAN PEMBAHASAN}

$\mathrm{Bab}$ ini membahas hasil penelitian berupa sistem pelabelan pada penerapan RSVP dan Segment Routing, serta performa traffic engineering dengan RSVP dan dengan Segment Routing, baik pada jalur utama maupun jalur cadangan berdasarkan hasil pengujian. Pada pengujian jalur utama dan jalur cadangan, performa dilihat berdasarkan parameter Quality of Service berupa latency, packet delivery ratio, packet loss ratio, dan throughput. Pada kondisi link mengalami kegagalan, pengukuran performa dikhususkan pada parameter packet loss ratio dan waktu yang dibutuhkan untuk berpindah dari jalur utama ke jalur cadangan. Nilai QoS tersebut diperoleh melalui pengujian dengan mengirim 100 kali paket ICMP melalui perintah ping. Pengujian dilakukan sebanyak 9 kali dengan berbagai beban, yaitu 50, 75, 100, 150, 250, 500, 750, 1000, 1250 byte.

Sebelum masuk ke pembahasan, disajikan topologi penelitian yang dapat dilihat pada Gambar 1 dan Gambar 2 . Pada kedua topologi diterapkan backup tunnel yang bertujuan agar ketika tunnel untuk jalur utama mati, traffic dapat diteruskan melalui jalur cadangan. Pada RSVP, backup tunnel dibuat dengan menerapkan Fast ReRoute (FRR). Pada Segment Routing, backup tunnel dibuat dengan menerapkan Topology Independent Loop Free Alternate (TI-LFA).

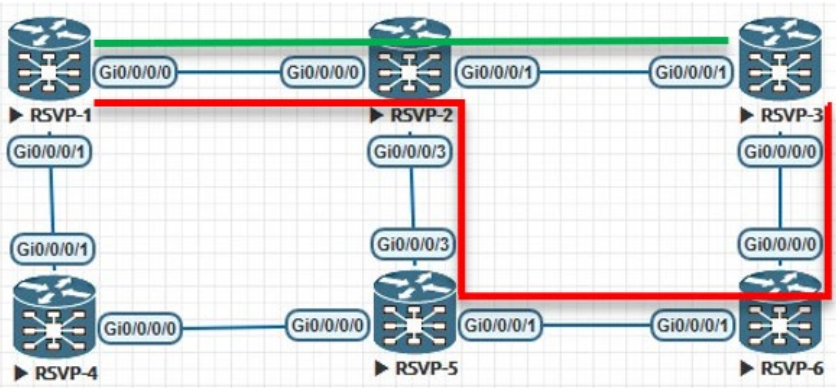

Gambar 1. Topologi Penerapan RSVP-TE

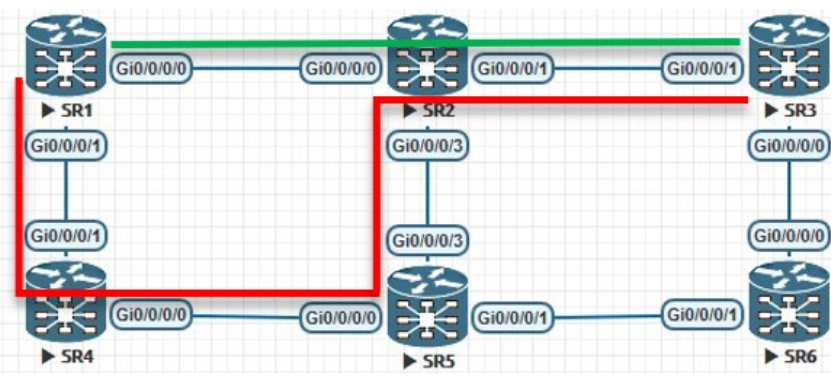

Gambar 2. Topologi Penerapan SR-TE
Garis warna hijau menunjukkan jalur utama, sedangkan garis warna merah menunjukkan jalur cadangan. Terdapat perbedaan dalam pemilihan jalur bertujuan untuk memberikan pemahaman tentang hasil implementasi yang sudah dilakukan. Backup link pada RSVP bisa diterapkan di router head-end maupun router yang berada di tengah-tengah jalur. Sedangkan pada Segment Routing, backup link hanya bisa diterapkan di router head-end. Meskipun rute jalur cadangan berbeda, jumlah hop yang dilewati sama dan tanpa dipengaruhi oleh kongesti pada link yang dilewati sehingga terhindar dari hal-hal yang mempengaruhi nilai QoS yang dibandingkan.

\section{A. Sistem Pelabelan}

Pada MPLS RSVP, label dialokasikan secara otomatis. Ketika mengaktifkan RSVP maka secara otomatis label didistribusikan untuk masing-masing node dengan nilai antara 24000 s.d. 1048575. Implementasi RSVP dilakukan dengan mendefinisikan interface yang dikehendaki di blok konfigurasi rsvp. Gambar 3 merupakan blok konfigurasi RSVP di suatu router.

$$
\begin{aligned}
& \text { rsvp } \\
& \text { interface GigabitEthernet } 0 / 0 / 0 / 0 \\
& ! \\
& \text { interface GigabitEthernet } 0 / 0 / 0 / 1 \\
& !
\end{aligned}
$$

Gambar 3. Blok Konfigurasi RSVP

Pada Segment Routing, range label diatur oleh Segment Routing Global Block (SRGB) dengan nilai antara 1600023999. Namun, range SRGB dapat diubah dengan salah satu tujuannya untuk menentukan range dari prefix segment yang terpisah dari range label untuk adjacency segment (routing OSPF). Implementasi Segment Routing berada di konfigurasi IGP, yaitu dengan mengkonfigurasi label prefix segment secara manual. Gambar 4 merupakan konfigurasi prefix segment di blok konfigurasi routing OSPF.

$$
\begin{aligned}
& \text { area } \theta \\
& \text { mpls traffic-eng } \\
& \text { interface Loopback } \theta \\
& \text { prefix-sid index } 1 \\
& \text { ! Gambar 4. Konfigurasi Prefix Segment }
\end{aligned}
$$

Segment Routing di MPLS menyederhanakan kinerja dari router dalam hal pelabelan dan dalam memelihara Label Switch Path (LSP). RSVP saling bekerjasama dengan IGP. IGP bertugas untuk menentukan jalur kemudian menyerahkan jalur ke RSVP untuk advertise label di jalur tersebut. Dalam memelihara LSP, antar router RSVP saling mengirim pesan SREFRESH (PATH dan RESV) yang berfungsi untuk membuat state tetap aktif pada Label Switch Path (LSP). Sedangkan pada Segment Routing, label yang sudah dialokasikan akan didistribusikan oleh IGP ke semua node 
yang mengaktifkan Segment Routing, tanpa perlu protocol signaling. Pada Segment Routing, link antar router dipelihara oleh Adjacency-SID.

\section{B. Pengujian QoS pada Jalur Utama}

Sub bab ini membahas hasil pengujian QoS pada jalur utama, berikut dijelaskan masing-masing parameternya.

\section{Hasil Pengujian Latency}

Pengukuran Latency dilakukan untuk mengetahui waktu tempuh yang diperlukan oleh paket data dari pengirim ke tujuan dan kembali lagi ke pengirim. Gambar 5 merupakan grafik perbandingan nilai latency dari penerapan RSVP dan Segment Routing pada masing-masing besar paket. Sebagian besar hasil pengujian menunjukkan bahwa nilai latency keduanya sama besarnya. Perbedaan terdapat pada pengujian dengan paket 250 dan 500 byte. Pada pengujian dengan paket sebesar 250 byte, nilai latency RSVP lebih kecil daripada latency Segment Routing. Pada pengujian dengan paket sebesar 500, nilai latency RSVP lebih besar daripada latency pada Segment Routing. Dari sembilan pengujian jika diratarata, nilai latency pada penerapan RSVP sama dengan latency pada penerapan Segment Routing, yaitu sebesar 5,778 ms.

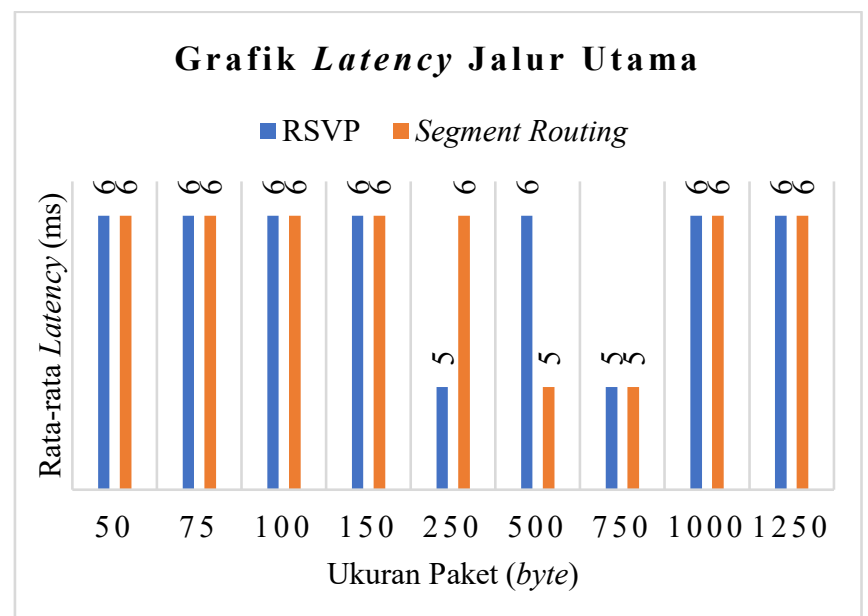

Gambar 5. Grafik Latency Jalur Utama

2. Hasil Pengujian Packet Delivery Ratio dan Packet Loss Ratio

Tabel 1. Hasil Pengujian Packet Delivery Jalur Utama

\begin{tabular}{rrrr}
\hline \multirow{2}{*}{$\begin{array}{c}\text { Uji } \\
\text { ke- }\end{array}$} & $\begin{array}{c}\text { Ukuran } \\
\text { Paket (byte) }\end{array}$ & \multicolumn{2}{c}{ Nilai Packet Delivery (\%) } \\
\hline 1 & 50 & 100 & Segment Routing \\
\hline 2 & 75 & 100 & 100 \\
\hline 3 & 100 & 100 & 100 \\
\hline 4 & 150 & 100 & 100 \\
\hline 5 & 250 & 100 & 100 \\
\hline 6 & 500 & 100 & 100 \\
\hline 7 & 750 & 100 & 100 \\
\hline 8 & 1000 & 100 & 100 \\
\hline 9 & 1250 & 100 & 100 \\
\hline
\end{tabular}

Packet delivery ratio merupakan perbandingan banyaknya paket yang berhasil diterima dengan banyaknya paket yang dikirim. Tabel 1 menunjukkan bahwa packet delivery ratio di semua pengujian baik pada traffic engineering dengan RSVP maupun pada Segment Routing bernilai 100\%. Ini artinya semua paket yang dikirim dapat diterima oleh tujuan dan dikembalikan lagi ke pengirim.

Packet loss merupakan banyaknya paket yang hilang ketika proses pengiriman. Packet loss dapat dihitung dengan mengurangi paket yang dikirim dengan paket yang diterima. Oleh karena itu, packet loss merupakan kebalikan dari packet delivery. Jadi, nilai packet loss ratio dari RSVP dan Segment Routing jalur utama adalah $0 \%$.

\section{Hasil Pengujian Throughput}

Throughput merupakan besarnya data yang dapat dikirim pada jaringan dalam satuan waktu. Throughput adalah bandwidth aktual yang menyatakan kecepatan pengiriman data dengan satuan bits per second. Gambar 6 merupakan grafik perbandingan nilai throughput dari penerapan RSVP dan Segment Routing pada masing-masing besar paket. Dari sembilan pengujian tersebut jika dirata-rata, nilai throughput pada penerapan RSVP sebesar 1046,667 kbps dan pada penerapan Segment Routing sebesar 1092,778 kbps. Baik pada RSVP maupun Segment Routing, semakin besar paket yang dikirim, nilai throughput menjadi semakin besar. Throughput semakin bagus jika nilainya semakin besar. Dibandingkan dengan RSVP, grafik menunjukkan bahwa Segment Routing unggul di semua ukuran paket dalam pengujian. Oleh karena itu, Segment Routing dapat mengirimkan data dengan lebih cepat daripada RSVP.

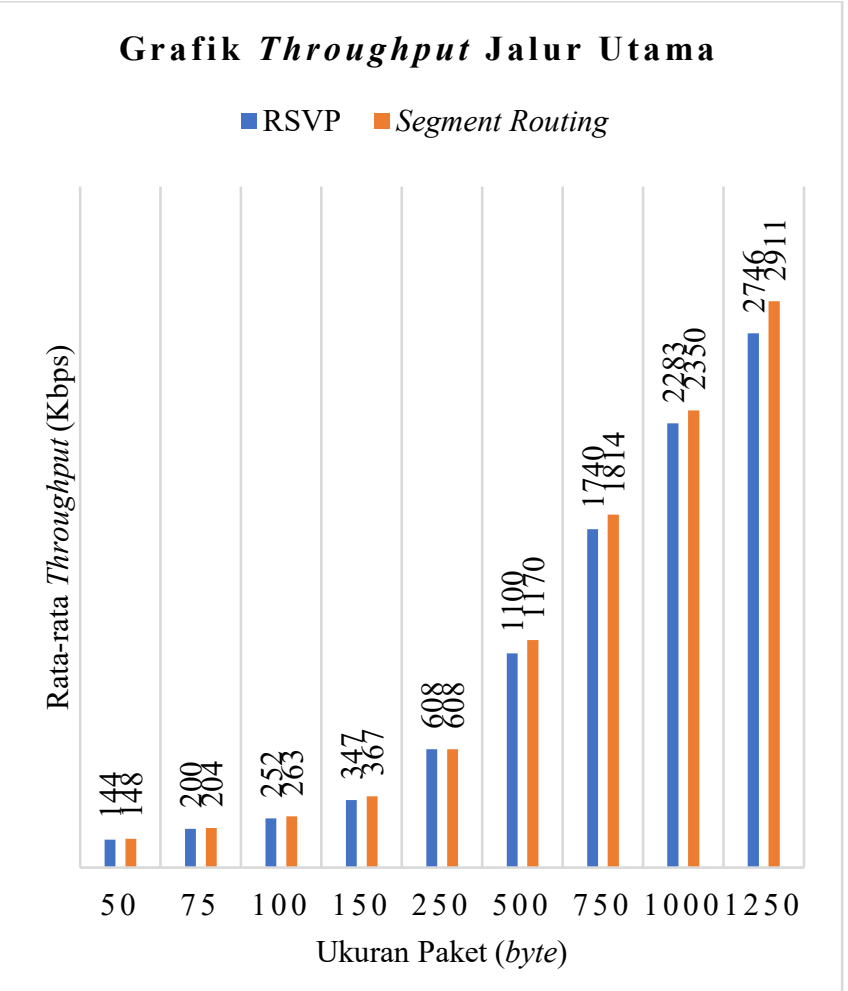

Gambar 6. Grafik Troughput Jalur Utama 


\section{Pengujian QoS pada Jalur Cadangan}

\section{Hasil Pengujian Latency}

Gambar 7 merupakan grafik hasil pengukuran latency jalur cadangan pada penerapan Fast Reroute di RSVP dan TILFA di Segment Routing. Dari sembilan pengujian tersebut jika dirata-rata, nilai latency pada penerapan Fast Reroute di RSVP sebesar 13,111 ms dan pada penerapan TI-LFA di Segment Routing sebesar 10,778 ms. Dapat dilihat melalui grafik pula bahwa di semua pengujian, latency dari RSVP lebih besar daripada Segment Routing. Oleh karena itu, latency pada Segment Routing lebih bagus daripada latency pada RSVP. Dengan kata lain, Segment Routing dapat mengirim data dengan lebih cepat daripada RSVP.

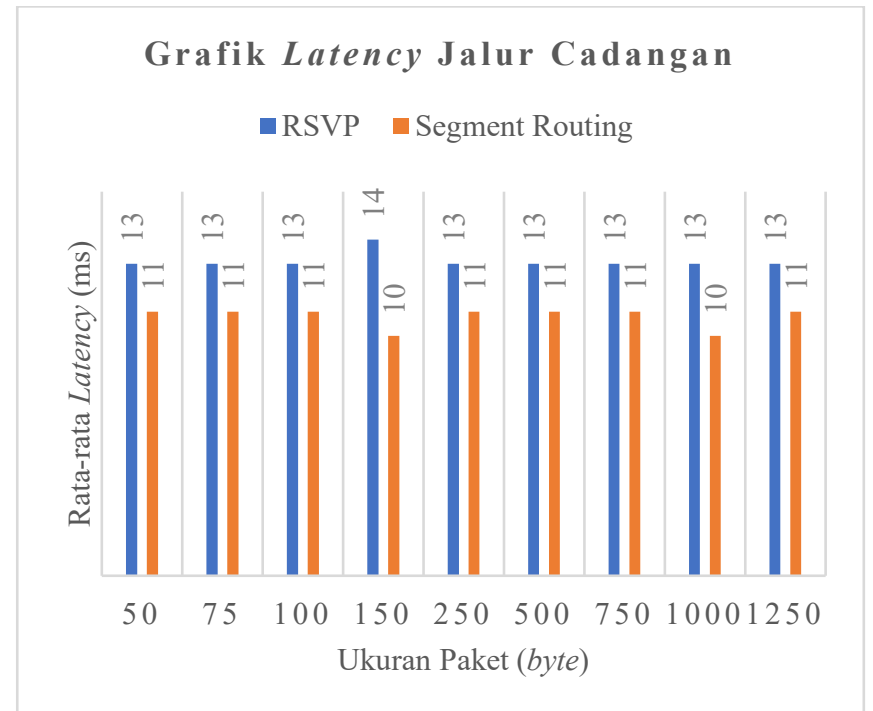

Gambar 7. Grafik Latency Jalur Cadangan

2. Hasil Pengujian Packet Delivery Ratio dan Packet Loss Ratio

Tabel 2. Hasil Pengujian Packet Delivery Jalur Cadangan

\begin{tabular}{rrrr}
\hline \multirow{2}{*}{$\begin{array}{c}\text { Uji } \\
\text { ke- }\end{array}$} & $\begin{array}{c}\text { Ukuran } \\
\text { Paket (byte) }\end{array}$ & \multicolumn{2}{c}{ Nilai Packet Delivery (\%) } \\
\cline { 3 - 4 } & RSVP & Segment Routing \\
\hline 1 & 50 & 100 & 100 \\
\hline 2 & 75 & 100 & 100 \\
\hline 3 & 100 & 100 & 100 \\
\hline 4 & 150 & 100 & 100 \\
\hline 5 & 250 & 100 & 100 \\
\hline 6 & 500 & 100 & 100 \\
\hline 7 & 750 & 100 & 100 \\
\hline 8 & 1000 & 100 & 100 \\
\hline 9 & 1250 & 100 & 100 \\
\hline
\end{tabular}

Nilai packet delivery jalur cadangan pada penerapan traffic engineering dengan RSVP dan Segment Routing disajikan pada Tabel 2. Tabel 2 menunjukkan bahwa packet delivery ratio di semua pengujian baik pada traffic engineering dengan RSVP maupun pada Segment Routing bernilai $100 \%$. Ini artinya semua paket yang dikirim dapat diterima oleh tujuan dan dikembalikan lagi ke pengirim. Nilai packet loss merupakan kebalikan dari nilai packet delivery. Jadi, nilai packet loss ratio dari RSVP dan Segment Routing jalur cadangan adalah $0 \%$.

\section{Hasil pengujian Throughput}

Gambar 8 merupakan grafik perbandingan nilai throughput dari penerapan RSVP dan Segment Routing pada masing-masing besar paket. Dari sembilan pengujian tersebut jika dirata-rata, nilai throughput pada penerapan RSVP sebesar 486,111 kbps dan pada penerapan Segment Routing sebesar 570,111 kbps. Baik pada RSVP maupun Segment Routing, semakin besar paket yang dikirim, nilai throughput menjadi semakin besar. Dibandingkan dengan RSVP, grafik menunjukkan bahwa Segment Routing unggul di semua ukuran paket dalam pengujian. Throughput semakin bagus jika nilainya semakin besar, sehingga hasil pengujian throughput dari Segment Routing lebih bagus dan dapat mengirim data dengan lebih cepat daripada RSVP.

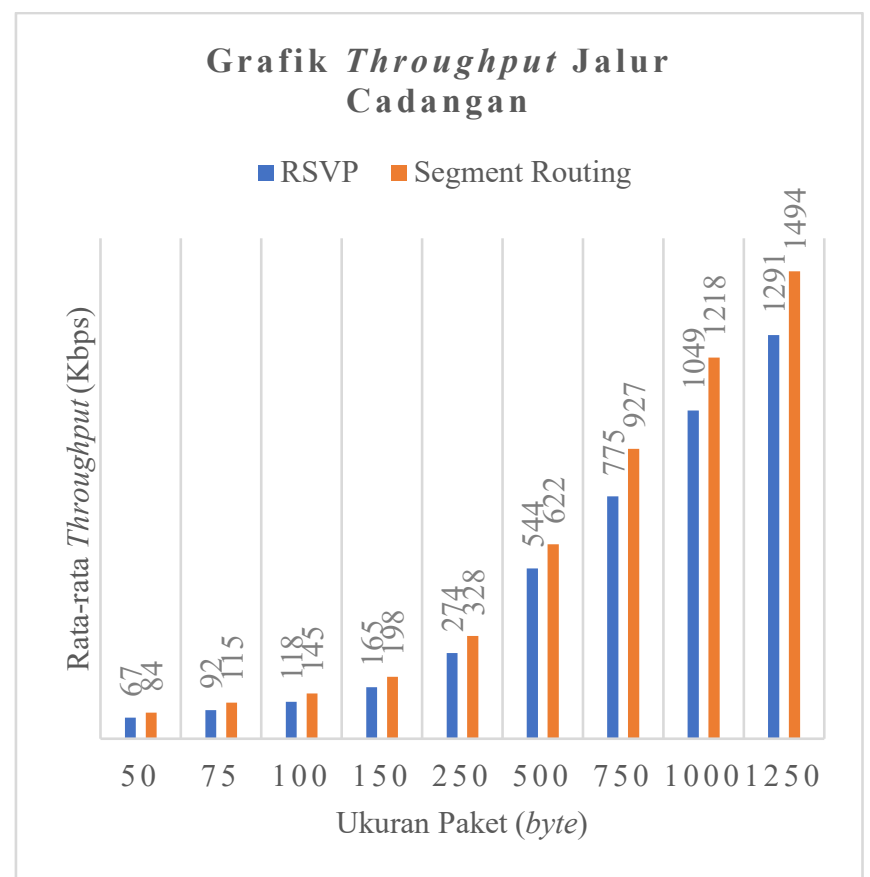

Gambar 8. Grafik Throughput Jalur Cadangan

D. Pengujian Perpindahan Jalur Utama ke Jalur Cadangan

1. Hasil Pengujian Packet Loss

Pemutusan koneksi pada suatu jalur yang sedang digunakan memungkinkan terjadinya paket yang hilang. Bagian ini akan memaparkan hasil pengujian baik pada RSVP maupun Segment Routing. Jumlah packet loss dihitung dari informasi yang tertera pada proses ping.

Tabel 3 merupakan hasil pengukuran packet loss pada penerapan jalur cadangan Fast Reroute pada RSVP dan TILFA pada Segment Routing. Semua pengujian baik dengan RSVP maupun Segment Routing berhasil mengirimkan 99 dari 100 paket. Oleh karena itu, setiap pengujian mempunyai nilai packet loss sebesar $1 \%$. 
Tabel 3. Nilai Packet Loss Perpindahan Jalur

\begin{tabular}{|c|c|c|c|}
\hline \multirow{2}{*}{$\begin{array}{l}\text { Uji } \\
\text { ke- }\end{array}$} & \multirow{2}{*}{$\begin{array}{c}\text { Ukuran } \\
\text { Paket (byte) }\end{array}$} & \multicolumn{2}{|c|}{ Nilai Packet Loss (\%) } \\
\hline & & RSVP & Segment Routing \\
\hline 1 & 50 & 1 & 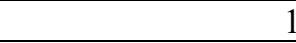 \\
\hline 2 & 75 & 1 & 1 \\
\hline 3 & 100 & 1 & 1 \\
\hline 4 & 150 & 1 & 1 \\
\hline 5 & 250 & 1 & 1 \\
\hline 6 & 500 & 1 & 1 \\
\hline 7 & 750 & 1 & 1 \\
\hline 8 & 1000 & 1 & 1 \\
\hline 9 & 1250 & 1 & 1 \\
\hline
\end{tabular}

2. Waktu yang Dibutuhkan untuk Perpindahan Jalur

Selain memungkinkan terjadinya paket yang hilang, berpindahnya jalur utama ke jalur cadangan tentu membutuhkan proses dengan waktu tertentu. Proses pengujian dimonitor dengan menggunakan Wireshark. Wireshark menampilkan informasi tentang waktu dilakukannya request dan reply paket ICMP. Pada penelitian ini, informasi tersebut dimanfaatkan untuk mencari waktu yang dibutuhkan dalam perpindahan jalur dari jalur utama ke jalur cadangan.

Perbandingan waktu yang dibutuhkan untuk berpindah jalur dari jalur utama ke jalur cadangan pada penggunaan RSVP dan Segment Routing disajikan pada Tabel 4.11. Dari kesembilan pengujian tersebut diperoleh rata-rata waktu yang dibutuhkan untuk berpindah jalur dengan RSVP Fast Reroute yaitu 2,017 s. Pada penerapan Segment Routing TI-LFA yaitu 2,015 s. Oleh karena itu, Segment Routing dapat berpindah jalur 2 ms lebih cepat daripada RSVP.

Tabel 4. Hasil Pengujian Waktu Perpindahan Jalur

\begin{tabular}{rrrr}
\hline Uji & Ukuran & \multicolumn{2}{c}{ Waktu Perpindahan Jalur (s) } \\
\cline { 3 - 4 } ke- & Paket (byte) & RSVP & Segment Routing \\
\hline 1 & 50 & 2,018 & 2,016 \\
\hline 2 & 75 & 2,013 & 2,013 \\
\hline 3 & 100 & 2,015 & 2,013 \\
\hline 4 & 150 & 2,020 & 2,019 \\
\hline 5 & 250 & 2,022 & 2,020 \\
\hline 6 & 500 & 2,015 & 2,019 \\
\hline 7 & 750 & 2,016 & 2,010 \\
\hline 8 & 1000 & 2,021 & 2,012 \\
\hline 9 & 1250 & 2,015 & 2,016 \\
\hline
\end{tabular}

\section{KESIMPULAN}

Berdasarkan pembahasan yang sudah dilakukan, dapat disimpulkan bahwa Segment Routing di MPLS menyederhanakan kinerja dari router dalam hal pelabelan dan dalam memelihara Label Switch Path (LSP). Pada pengujian QoS antara penerapan RSVP dan Segment Routing baik pada jalur utama maupun jalur cadangan bernilai sama untuk parameter packet delivery ratio, dan packet loss ratio sedangkan latency keduanya sama pada jalur utama saja. QoS dari Segment Routing lebih bagus daripada RSVP pada pengujian latency jalur cadangan dan throughput baik jalur utama maupun jalur cadangan. Adapun Segment Routing dapat berpindah jalur dengan lebih cepat.

\section{REFERENSI}

[1] Tim APJII. (2018). Potret Zaman Now Pengguna dan Perilaku Internet Indonesia. Buletin APJII, pp. 1-7

[2] Systems, C. (2014). Implementing Cisco Service Provider Next-Generation Core Network Services Student Guide Vol 1 (Vol. 2). Cisco

[3] Filsfils, C., Previdi, S., \& Ginsberg, L. (2018). Segment Routing Architecture (Paper)

[4] Das, K. (2015). Implementation of Fast reroute configuration with link and node protection in MPLSTE. Diakses dari https://www.researchgate.net/ publication/307082533_Implementation_of_Fast_rerou te_configuration_with_link_and_node_protection_in_ MPLS-TE

[5] Wulansari, F., Munadi, R., \& Mayasari, R. (2016). Analisis Jaringan MPLS-TE Fast Reroute Menggunakan Metode QoS Diffserv Berbasis Server OpenIMSCore. Seminar Nasional Teknologi Informasi dan Komunikasi 2016 (Sentika 2016), pp. 18-19

[6] Prjevara, P., \& Makioui, F. (2018). Optimal network design of SURFnet8, using TI-LFA and Segment Routing (Paper). Diakses dari http://www.scriptiesonline. uba.uva.nl/document/660552

[7] Vonny, Z. (2017). Implementasi Teknologi MPLS Menggunakan Routing Protokol OSPF Pada Router Mikrotik (Tugas Akhir). Diakses dari: https://openlibrary.telkomuniversity.ac.id/pustaka/1371 38/implementasi-teknologi-mpls-menggunakan-routing -protokol-ospf-pada-router-mikrotik.html

[8] Purnomo, R.R.H. (2013). LKP : Simulasi MPLS(Multi Protocol Label Switch) Pada Perusahaan Daerah Air Minum Kota Surabaya (STIKOM Surabaya). Diakses dari http://sir.stikom.edu/id/eprint/43/

[9] Kaur, D., \& Kumar, E. D. (2015). Comparative Analysis of MPLS Signaling Protocols. International Journal of Computer Science Trends and Technology (IJCST), 3(4), July-August 2015, pp. 169-177. Diakses dari https://doi.org/10.1201/9781420013870.ch4

[10] Mota, R. (2018). Segment Routing with Use Cases. ACG Research, pp. 5-28. Diakses dari https://doi.org/ 10.13140/RG.2.2.27036.13446

[11] Dzerkals, U. (2017). EVE-NG Professional Cookbook. EVE-NG Limited. Diakses dari http://eveng.net/ images/EVE-COOK-BOOK-1.12.pdf. 